\title{
Reaction norm variation in a rare plant, Senecio integrifolius (Asteraceae)
}

\author{
S. ANDERSSON* \& B. WIDÉN \\ Department of Systematic Botany, University of Lund, O.Vallgatan 18-20, S-223 61 Lund, Sweden
}

\begin{abstract}
This study examines the pattern of reaction norm variation and the extent to which genetic constraints could prevent the evolution of broader ecological tolerance in Senecio integrifolius, a rare and declining plant in Sweden. Following the establishment of biparental progenies, we planted seedlings from each full-sib family in two greenhouse environments: full daylight and 50 per cent shade. A 2-year demographic study indicated that full-sib genotypes representing a large population at a site with a fine-scale mosaic habitat (meadow with clumps of shrubs) had a significantly greater overall performance across the environments and a lower sensitivity to a drastic reduction in light intensity than genotypes representing a small and patchily distributed population at a site without spatial variation (meadow exposed to full sun), confirming the supposition of more broadly adapted genotypes in a large population subject to selection across a wider range of microhabitats. There was a significant average effect of genotype for all traits but we failed to detect within-population variation in phenotypic response $(\mathrm{G} \times \mathrm{E})$ for direct components of fitness and conclude that there is little potential for specialization to particular light regimes. Across-environment correlations using full-sib means were small and positive and there was no change in the ranking of population means across the two environments, implying a lack of strong trade-offs within the reaction norm. However, the changes in ecological amplitude may not be of sufficient magnitude to permit long-term survival of remaining populations, as implied by the rapid decline of S. integrifolius in Sweden.
\end{abstract}

Keywords: ecological tolerance, genetic variation, rarity, reaction norm, Senecio integrifolius, trade-off.

\section{Introduction}

The reaction norm, i.e. the response of a genotype to a specific range of environmental conditions, can evolve by natural selection when there is spatial heterogeneity in selection pressures and extensive gene flow between sites with different selection regimes. Yet, despite recent attempts to predict how the average reaction norm will evolve in different systems (Levins, 1968; Via \& Lande, 1985; Stearns \& Koella, 1986; Van Tienderen, 1991; Gabriel \& Lynch, 1992; Gomulkiewicz \& Kirkpatrick, 1992), few efforts have been made to demonstrate that the reaction norm can represent a target of selection in natural populations (e.g. Weis \& Gorman, 1990).

Adaptive changes in the reaction norm facilitate the evolution of generalists adapted to multiple environments, particularly when the scale of spatial heterogeneity is small relative to the mean distance of gene

*Correspondence. flow (Bradshaw, 1965; Levins, 1968). Hence, to the extent that populations are sufficiently large for selection to over-ride the effects of genetic drift, an alternative means of inferring reaction norm evolution is to compare the response of plants originating from sites with different levels of environmental heterogeneity (Cook \& Johnson, 1968; Hickman, 1975; Zimmerman, 1976; Wilken, 1977; Bazzaz \& Carlson, 1982; Silander, 1985; Lotz \& Spoormakers, 1988; Andersson, 1989). For characters that are under persistent directional selection (fitness components), one would expect the highest overall performance (broad ecological tolerance) of genotypes from populations experiencing selection across a wide range of microhabitats.

Besides revealing different histories of selection, the common-garden approach (extended to multiple environments) also provides an opportunity to examine whether there is sufficient variation among genotypes within populations for further adjustment of the average reaction norm. To date, numerous studies have 
documented the genetic variability necessary for response to selection (or genetic drift) and visualized the variation as reaction norm diagrams which are useful for interpreting statistically significant genotype-environment interactions (e.g. Westerman, 1970; Shaw, 1986; Taylor \& Aarssen, 1988; Bierzychudek, 1989; Mazer \& Schick, 1991; Schmitt et al., 1992; for animals see Gupta \& Lewontin, 1982; Via, 1984a; Newman, 1988; Trexler \& Travis, 1990; Weis \& Gorman, 1990).

Reaction norm evolution can be constrained by negative genetic correlations between character states expressed in different environments (Via \& Lande, 1985), by trade-offs between the performance in a broad range of environments and in any single (optimum) environment (Gabriel \& Lynch, 1992) and by other costs associated with being a generalist (Van Tienderen, 1991). Partly because of the complex experimental design needed to estimate the additive genetic (co)variance for reaction norm parameters (e.g. Via, 1984a,b; Weis \& Gorman, 1990), there have been few attempts to reveal the existence of such trade-offs (e.g. Huey \& Hertz, 1984; Via, 1984b; Shaw, 1986; Taylor \& Aarssen, 1988; Bennett et al., 1990; Fry, 1990; Miller \& Schemske, 1990). Assuming that largescale patterns of variation reflect underlying (genetic) constraints, a comparison of genotypes from different populations grown across the same set of environments could yield insights into the realized trade-offs occurring within the reaction norm.

Rare species appear to have reproductive characteristics that differ from those of more common and widespread taxa (Kunin \& Gaston, 1993) but relatively little is known about the mechanism(s) that could be responsible for rarity itself. For instance, it is possible that rare and declining species lack the genetic variation required for rapid adjustment of the reaction norm in a changing environment. However, although rare and narrowly distributed species tend to have less allozyme diversity than geographically widespread species (Hamrick \& Godt, 1990), there have been few attempts to examine whether rarity is associated with low genetic variance for ecological tolerance.

In the present investigation of Senecio integrifolius, a locally rare plant with a narrow ecological amplitude in Sweden, we examined the potential for adaptive changes in the reaction norm by comparing the response of genotypes representing two widely different localities grown across the same set of light environments. We predicted a greater tolerance to changes in light intensity of genotypes from a historically large population representing a mosaic environment in which there is small-scale spatial variation in light intensity (selection across a wide range of micro- habitats) than from a uniform site where plants occur in small patches (selection across a narrow range of microhabitats and a great potential for genetic drift). Our data also provide a possibility to test whether increased adaptation to shade (if any) has been achieved at the expense of decreased adaptation to full sunshine, i.e. whether genetic trade-offs within the reaction norm have prevented $S$. integrifolius from exploiting a wider range of light environments.

\section{Materials and methods}

In Sweden, Senecio integrifolius (Asteraceae) is a rare herbaceous perennial confined to dry meadows on calcareous soil in the southernmost province (Skåne). Flowering occurs from May to June when the vertical root-stock develops one or several stems with a variable number of flower heads arranged in terminal corymbs. The plants are self-incompatible (Widén, 1991a) and cross-pollinated flowers develop into oneseeded indehiscent fruits (achenes) dispersed by the wind. Most seeds germinate during the first autumn after dispersal and no seed bank is formed (Widén, 1987).

During the past decades, $S$. integrifolius has disappeared from many localities in Sweden and only eight populations are currently known, some of which are rapidly diminishing in size. One major cause for the recent decline of the species is increased competition from surrounding vegetation (shading) due to the use of fertilizer and cessation of grazing by cattle (Widén, 1987).

The plant material used in this investigation was derived from seed collected at two of the remaining localities (75 km apart). The 'Benestad' population (SE Skåne), sampled and mapped in 1985, comprises 30-250 flowering individuals per year in nine small stands, 10-50 m apart, on a heavily grazed pasture on a south-facing slope without shrubs, a highly uniform habitat as regards light regime (all plants exposed to full sun; Fig. 1). Historical records and examination of air photographs indicate heavy grazing for at least 50 years (Regnéll, 1976). The narrow range of light environments imposing selection on this population combined with a potential for genetic drift within patches of plants may retard the evolution of broad ecological tolerance at the Benestad site.

In the larger and more continuous 'Grödby' population (NE Skåne), sampled and mapped in 1984, $S$. integrifolius occurs in a moderately grazed pasture (100-3000 flowering plants per year) consisting of a mosaic of open patches with a short grass sward and clumps of bushes (Rosa spp., Juniperus communis, etc.) which shade parts of the population. When the Grödby 

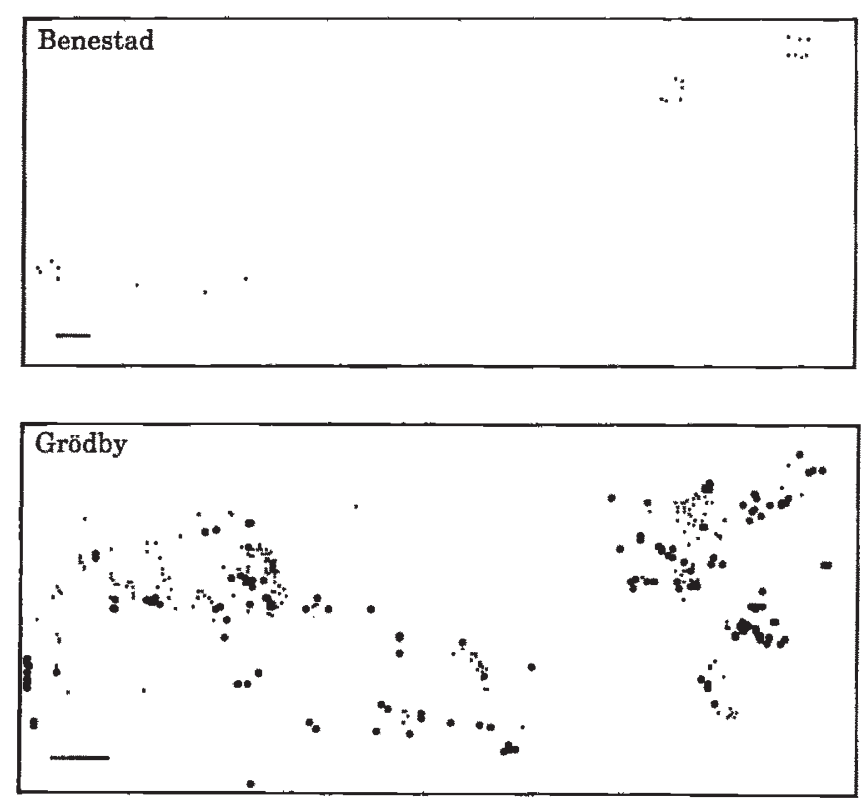

Fig. 1 Map showing the distribution of plants of $S$. integrifolius exposed to full sun (small dots) and shaded by shrubs (large dots) at the Benestad and Grödby sites. Scale bar $=10 \mathrm{~m}$.

population was sampled for the present study, 44 per cent of the plants were shaded by shrubs (Fig. 1). This site had been more heavily grazed previously (Widén, 1987), suggesting recent expansion of shrubs. Given the efficient wind dispersal of $S$. integrifolius and the small scale of the spatial variation at this locality, there is a high probability that a seed will germinate in a site that is markedly different from the site of the parent plants. Hence, broad ecological tolerance may have evolved as a response to the wide range of light conditions encountered by this population.

In the summer of 1989, one of us (B.W.) established a series of biparental progenies by reciprocally crossing pairs of plants from each of the two populations. Matings were restricted to plants in different maternal families, each family representing the offspring of a plant sampled in the field. All crosses were performed under insect-free conditions. Because $S$. integrifolius is self-incompatible, we assume that no (or very few) selfed progeny were included in the sibships. In the autumn, we germinated the seeds on moist filter paper in Petri dishes, split the seedlings of each maternal family within each cross into two samples, and assigned the two groups to different environments in an unheated glasshouse: one sample was exposed to full daylight throughout the experiment whereas the other was grown under a polythene net (about 50 per cent light reduction). The shade environment was applied 10 months after transplantation to simulate a decrease in light intensity within the lifespan of individual plants, a likely scenario in the long-lived $S$. integrifolius considering the fact that most seedlings establish in open patches with little competition from other plants and the rapid invasion of shrubs and closed herbaceous communities following the cessation of grazing (Widén, 1987). All seedlings (about 10 per maternal sibship and light regime) were randomly positioned within each treatment.

We censused the plants at regular intervals during a 2-year period and determined the following measures of performance for each of the maternal sibships within each environment: (i) the average lifespan (months); (ii) the proportion of plants that survived until the experiment was terminated (October 1991); (iii) the average date of first flowering measured as the number of days after 1 April 1991; and (iv) the average number of heads of plants flowering in 1991. Flowering date is negatively correlated with plant vigour (Widén, 1991b) and has a potential effect on the pollination success with early flowering plants being more successful than late ones (Widén, 1991a) whereas the other variables contribute directly to lifetime fitness. Although some of the variables are computationally dependent, each is expected to provide at least some information not revealed by the other variables. We collapsed the data into maternal sibship means such that each full-sib group was represented by the two reciprocal family means in each light treatment. In this way, we enhanced the balance of the design, made the distributions more continuous for some of the variables and improved the fit to normality; only survival rate had to be transformed prior to analysis (arcsine).

A nested, two-factor analysis of variance (ANOVA) using the Procedure GLM in SAS (type III expected mean squares) was used to partition the total variance into components due to environment (light regime), population origin (Benestad vs. Grödby), full-sibship (nested within population), population-by-environment interaction and sibship-by-environment interaction. A significant average effect of a main factor (environment, population or sibship) reveals differences in the overall mean, i.e. in the elevation of the reaction norm whereas a significant interaction term indicates a nonparallel response to the environment. Sibship was treated as a random effect whereas population and environment were considered as fixed effects (see Table 1 for mean squares used as denominators in the $F$-tests).

The variance among biparental progenies is equal to the covariance of full-sibs, which is $V=(1 / 2) V_{\mathrm{A}}+(1 / 4)$ $V_{\mathrm{D}}+V_{\mathrm{m}}$, where $V_{\mathrm{A}}$ is equal to the additive genetic variance, $V_{\mathrm{D}}$ is the dominance variance arising from nonadditive interactions between alleles at the same 
Table 1 Nested, two-factor ANOVA on four performance traits with sibship nested within population

\begin{tabular}{|c|c|c|c|c|c|}
\hline $\begin{array}{l}\text { Source of } \\
\text { variation }\end{array}$ & d.f. & $\begin{array}{l}\text { Mean } \\
\text { Square }\end{array}$ & $\begin{array}{l}\text { Denominator } \\
\quad \text { for } F\end{array}$ & $F$ & $\begin{array}{c}\text { Variance } \\
\text { component }(\%)\end{array}$ \\
\hline \multicolumn{6}{|l|}{ Lifespan } \\
\hline 1. Population & 1 & 24.76 & 2 & $1.99 \mathrm{NS}$ & 0.4 \\
\hline 2. Sibship & 96 & 12.44 & 6 & $2.01^{* * * *}$ & 10.4 \\
\hline 3. Light treatment $(\mathbf{L})$ & 1 & 1462.66 & 5 & $291.26^{* * *}$ & 47.9 \\
\hline 4. Pop $\times L$ & 1 & 32.94 & 5 & $6.56^{*}$ & 1.8 \\
\hline 5. Sibship $\times$ L & 96 & 5.02 & 6 & $0.81 \mathrm{NS}$ & 0.0 \\
\hline 6. Residual & 196 & 6.19 & & & 39.9 \\
\hline \multicolumn{6}{|l|}{ Survivorship } \\
\hline 1. Population & 1 & 0.38 & 2 & $5.90^{*}$ & 1.2 \\
\hline 2. Sibship & 96 & 0.06 & 6 & $1.55^{* *}$ & 4.2 \\
\hline 3. Light treatment $(\mathbf{L})$ & 1 & 16.50 & 5 & $406.48^{* * *}$ & 62.4 \\
\hline 4. Pop $\times \mathrm{L}$ & 1 & 0.26 & 5 & $6.40^{*}$ & 1.6 \\
\hline 5. Sibship $\times \mathrm{L}$ & 96 & 0.04 & 6 & $0.99 \mathrm{NS}$ & 0.0 \\
\hline 6. Residual & 196 & 0.04 & & & 30.5 \\
\hline \multicolumn{6}{|l|}{ Flowering time } \\
\hline 1. Population & 1 & 652.47 & 2 & $24.82^{* * * *}$ & 3.2 \\
\hline 2. Sibship & 96 & 26.29 & 6 & $2.67^{* * *}$ & 4.1 \\
\hline 3. Light treatment $(\mathbf{L})$ & 1 & 15504.06 & 5 & $1111.40^{* * * * *}$ & 79.0 \\
\hline 4. Pop $\times L$ & 1 & 194.58 & 5 & $13.95^{* * *}$ & 1.8 \\
\hline 5. Sibship $\times \mathrm{L}$ & 96 & 13.95 & 6 & $1.42^{*}$ & 2.1 \\
\hline 6. Residual & 196 & 9.83 & & & 9.8 \\
\hline \multicolumn{6}{|l|}{ Head number } \\
\hline 1. Population & 1 & 76.68 & 2 & $21.78^{* * *}$ & 7.7 \\
\hline 2. Sibship & 96 & 3.52 & 6 & $2.65^{* * *}$ & 11.4 \\
\hline 3. Light treatment $(\mathbf{L})$ & 1 & 449.74 & 5 & $258.47^{* * *}$ & 47.3 \\
\hline 4. $P o p \times L$ & 1 & 10.31 & 5 & $5.92 *$ & 1.8 \\
\hline 5. Sibship $\times L$ & 96 & 1.74 & 6 & $1.31 \mathrm{NS}$ & 4.3 \\
\hline 6. Residual & 196 & 1.33 & & & 27.5 \\
\hline
\end{tabular}

Population and light treatment were considered fixed and sibship random.

${ }^{*} P \leqslant 0.05,{ }^{* *} P \leqslant 0.01,{ }^{* * *} P \leqslant 0.001, \mathrm{NS}$ : not significant $(P>0.05)$.

loci and $V_{\mathrm{m}}$ is the variance due to common environment, including non-nuclear maternal effects (Falconer, 1981). Our design provides only an upper limit to the amount of heritable variation directly available to selection $\left(V_{\mathrm{A}}\right)$ but we assume that most of the maternal effects have been removed by using the two maternal sibship means within each full-sib family as replicates.

The response to different light intensities of each full-sibship (averaged across maternal sibship means) was displayed graphically as reaction norms and quantified for each variable as the difference between the mean value of the variable in full daylight and its mean value in shade; other methods of estimating the amount of response (coefficient of variation, etc.) gave essentially similar results and provided little additional insight (data not shown). We used the full-sib means to calculate the Pearson correlation coefficient between the same variable measured in the two light regimes. This parameter estimates the extent to which the character states expressed in two environments share a common genetic basis (Yamada, 1962; Falconer, 1981). For major components of fitness, the greatest potential for adaptation to both environments occurs when the across-environment correlation is zero or positive. Because of possible confounding effects of nonadditive sources of covariance (Falconer, 1981), we urge caution in the interpretation of the full-sib correlations.

\section{Results}

Overall, the main effects exerted a much stronger influence on plant performance than the interaction terms. Judging from the variance components (Table 
1), the most important source of variation in the present study was environment, with plants of $S$. integrifolius grown in full daylight living longer, flowering earlier and having a larger number of heads than those subject to the shade treatment (Table 2). The average effect of population was statistically significant for all but one variable (lifespan; Table 1), with plants from the heterogeneous Grödby site exceeding plants from the uniform Benestad site in survival rate and inflorescence production (Table 2). Sibship and the interaction between population and environment had a significant influence on all variables, but only flowering date was significantly affected by the sibship-environment interaction, suggesting little variation among genotypes within populations in their response to light intensity.

Figure 2 shows the variation among genotypes in the reaction norm for lifespan, flowering time and inflorescence production. As can be seen, the two populations overlapped considerably in the response of the full-sib families to the two light regimes. A comparison of the overall population means across the light regimes and the population means for each light regime, using the $t$-test on sibship means (Table 2), not only confirmed the overall difference between the two populations in the ANOvA (Table 1) but also revealed a significant difference in the amount of response; full-sib genotypes from the Grödby population showed a smaller decline in performance when grown in shade than did genotypes from the Benestad population.

Different measures of plant performance were either very weakly correlated or significantly positively correlated in the same light regime, contrasting early flowering genotypes with a high viability and a large head number from those with the opposite features (Table 3). A similar conclusion holds for the same variable expressed in different light regimes. Although further analyses using the $z$-transformation showed that all across-environment correlations were significantly smaller than $1(P<0.001)$, a full-sib genotype with a high performance in full daylight generally had a high performance when grown under shade (and vice versa).

\section{Discussion}

Reaction norm evolution in S. integrifolius

While numerous studies have documented adaptive plasticity (or wide ecological tolerance) in populations

Table 2 Means (standard deviations) for the performance of full-sibships raised in two light regimes

\begin{tabular}{lrrr}
\hline Variable & Benestad $(n=48)$ & Grödby $(n=59)$ & Student's $t$ \\
\hline Daylight & & & \\
$\quad$ Lifespan & $22.38(2.08)$ & $22.35(2.59)$ & $-0.080 \mathrm{NS}$ \\
Survivorship & $0.67(0.13)$ & $0.68(0.14)$ & $0.501 \mathrm{NS}$ \\
Flowering date & $35.04(4.04)$ & $33.37(3.49)$ & $-2.302^{*}$ \\
Head number & $6.55(1.20)$ & $7.08(1.29)$ & $2.149^{*}$ \\
Shade & & & \\
Lifespan & $17.71(2.14)$ & $18.99(2.29)$ & $2.972^{* *}$ \\
Survivorship & $0.28(0.11)$ & $0.39(0.12)$ & $4.831^{* * *}$ \\
Flowering date & $48.43(3.62)$ & $44.76(2.23)$ & $-6.452^{* * *}$ \\
Head number & $4.14(1.13)$ & $5.17(1.18)$ & $4.612^{* * *}$ \\
Average & & & \\
Lifespan & $20.05(1.77)$ & $20.67(2.11)$ & $1.635 \mathrm{NS}$ \\
Survivorship & $0.48(0.09)$ & $0.53(0.11)$ & $3.068^{* *}$ \\
Flowering date & $41.67(3.06)$ & $39.06(2.24)$ & $-5.110^{* * *}$ \\
Head number & $5.34(0.94)$ & $6.12(0.98)$ & $4.212^{* * * *}$ \\
Difference & & & \\
Lifespan & & & $2.892^{* * *}$ \\
Survivorship & $0.38(0.14)$ & $3.36(2.47)$ & $3.336^{* * * *}$ \\
Flowering date & $-13.55(4.36)$ & $-11.39(3.77)$ & $-2.747^{* *}$ \\
Head number & $2.48(1.34)$ & $1.90(1.51)$ & $2.054^{*}$ \\
\hline
\end{tabular}

'Average' and 'Difference' refer to the overall performance and the amount of response across the two environments, respectively.

${ }^{*} P \leqslant 0.05,{ }^{* *} P \leqslant 0.01,{ }^{* * *} P \leqslant 0.001$, NS: not significant $(P>0.05)$. 

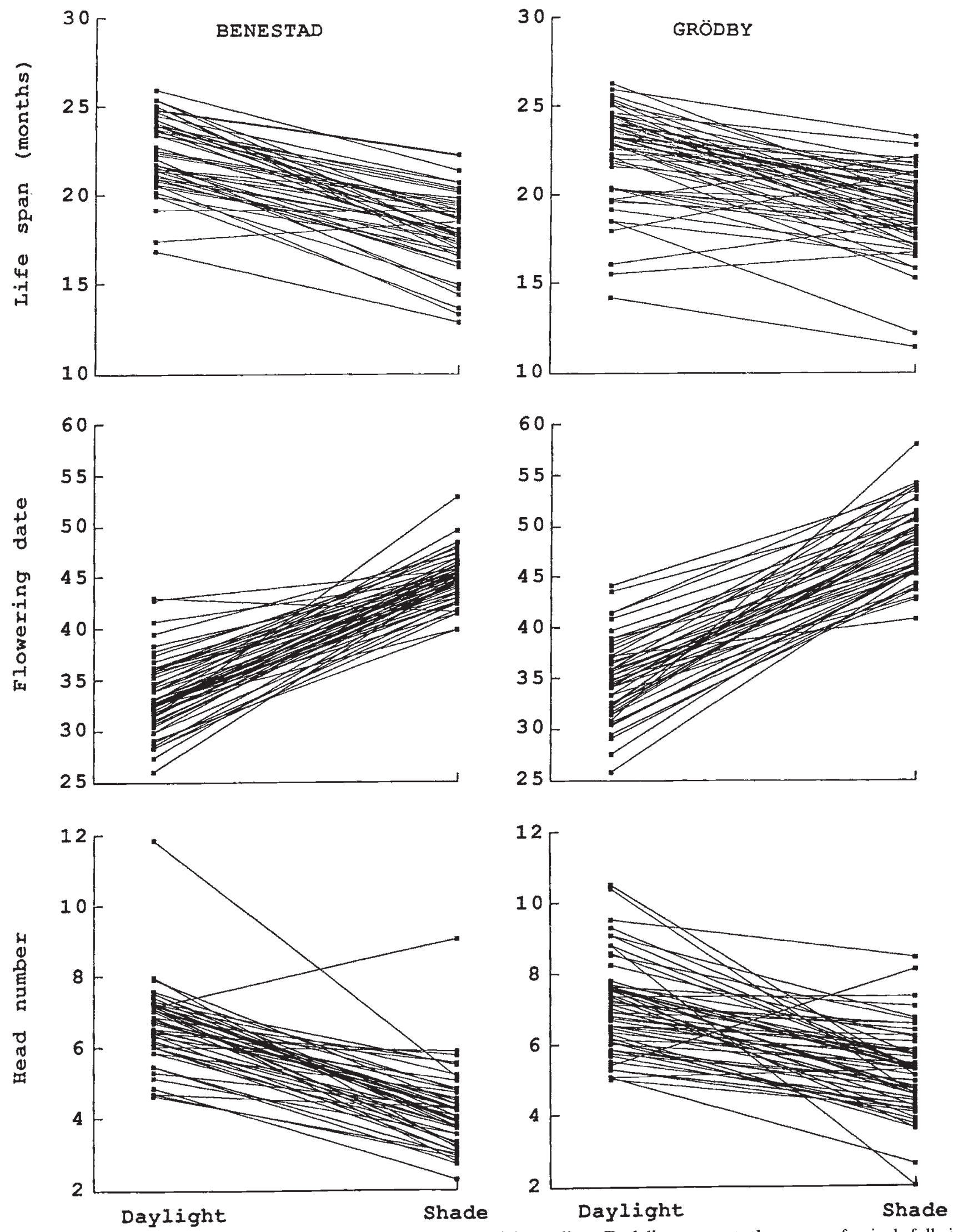

Fig. 2 Reaction norm diagrams for $S$. integrifolius across a steep light gradient. Each line connects the means of a single full-sib family grown in the two environments. Benestad represents the homogeneous site whereas Grödby represents the heterogeneous site (see Fig. 1). 
Table 3 Full-sib family mean correlations of four performance traits within and between light regimes. The within-environment correlation between lifespan and survivorship was not calculated because these variables are computationally dependent

\begin{tabular}{|c|c|c|c|c|c|c|c|c|c|}
\hline \multirow{2}{*}{$\begin{array}{l}\text { Population/ } \\
\text { variable }\end{array}$} & & \multicolumn{2}{|c|}{ Lifespan } & \multicolumn{2}{|c|}{ Survivorship } & \multicolumn{2}{|c|}{ Flowering date } & \multicolumn{2}{|c|}{ Head number } \\
\hline & & $\mathrm{D}$ & S & $\mathrm{D}$ & $S$ & $\mathrm{D}$ & $S$ & $\mathrm{D}$ & $S$ \\
\hline \multicolumn{10}{|c|}{ Benestad $(n=48)$} \\
\hline \multirow[t]{2}{*}{ Lifespan } & D & - & & & & & & & \\
\hline & $\mathrm{S}$ & $0.44^{*}$ & - & & & & & & \\
\hline \multirow[t]{2}{*}{ Survivorship } & $\mathrm{D}$ & - & $0.31^{*}$ & - & & & & & \\
\hline & $\mathrm{S}$ & 0.27 & - & 0.25 & - & & & & \\
\hline \multirow[t]{2}{*}{ Flowering date } & D & -0.04 & 0.00 & -0.06 & -0.10 & - & & & \\
\hline & $\mathrm{S}$ & $-0.32^{*}$ & -0.23 & $-0.33^{*}$ & $-0.30^{*}$ & $0.34^{*}$ & - & & \\
\hline \multirow[t]{2}{*}{ Head number } & $\mathrm{D}$ & -0.12 & -0.17 & -0.15 & -0.11 & 0.06 & -0.04 & - & \\
\hline & $S$ & 0.12 & -0.07 & 0.09 & -0.04 & 0.19 & $-0.36^{*}$ & $0.31^{*}$ & - \\
\hline \multicolumn{10}{|l|}{ Grödby $(n=59)$} \\
\hline \multirow[t]{2}{*}{ Lifespan } & $\mathrm{D}$ & - & & & & & & & \\
\hline & $\mathrm{S}$ & $0.49^{*}$ & - & & & & & & \\
\hline \multirow[t]{2}{*}{ Survivorship } & $\mathrm{D}$ & - & $0.41^{*}$ & - & & & & & \\
\hline & $\mathrm{S}$ & $0.40^{*}$ & - & $0.30^{*}$ & - & & & & \\
\hline \multirow[t]{2}{*}{ Flowering date } & $\mathrm{D}$ & $-0.36^{*}$ & -0.02 & $-0.41^{*}$ & -0.07 & - & & & \\
\hline & $\mathrm{S}$ & -0.24 & -0.10 & $-0.29^{*}$ & -0.21 & 0.19 & - & & \\
\hline \multirow[t]{2}{*}{ Head number } & $\mathrm{D}$ & $0.31^{*}$ & 0.19 & $0.34^{*}$ & 0.13 & -0.09 & -0.04 & - & \\
\hline & $S$ & 0.21 & 0.08 & 0.23 & 0.10 & 0.25 & -0.24 & 0.25 & \\
\hline
\end{tabular}

Values significantly greater or smaller than zero are shown by asterisks $(P<0.05$ to 0.001$)$.

D: daylight; S: shade.

of ecologically widespread species (e.g. Cook \& Johnson, 1968; Zimmerman, 1976; Silander, 1985; Lotz \& Spoormakers, 1988; Andersson, 1989), there have been few attempts to examine the potential for reaction norm evolution in rare or ecologically restricted species. Because of the numerous problems associated with experimental studies in populations of rare species such as $S$. integrifolius where manipulation has to be kept to a minimum, we used a glasshouse experiment to relate the ecological amplitude of two populations to local habitat conditions. Because of the low performance of plants when grown in shade (this study; Widén, 1991a,b) and the low tolerance of competition from invading communities (Widén, 1987), we hypothesize that shade represents a more novel environment than an open grass sward and assume that a high performance across a steep light gradient reflects a favourable phenotypic response in those characters that ultimately determine viability and fecundity, including traits that would have been difficult to measure directly (photosynthetic efficiency, etc.).

Striking differences in population size and in the patchiness of the habitat (Fig. 1) did not translate into large differences in reaction norm parameters, as shown by the substantial overlap between genotypes from the Benestad and Grödby populations in their response to different light intensities. However, closer examination of the data revealed small but significant population differences in the average reaction norm for various measures of fitness. While the overall performance across two contrasting light regimes was higher for plants representing the heterogeneous Grödby site than for plants derived from the uniform Benestad site (a difference in reaction norm elevation), there was also a tendency for this difference to be greater in the shade treatment, indicating a greater sensitivity of genotypes originating from the more homogeneous habitat (a difference in reaction norm slope).

It is tempting to attribute this differences to the local selection history, with the heterogeneous Grödby site favouring broadly tolerant genotypes capable of surviving and reproducing under a wide range of light intensities whereas genetic drift in the small and patchily distributed Benestad population may prevent selection in favour of high-light specialists at a uniform site exposed to full sunshine. If this interpretation is correct, our data are consistent with the idea that the average reaction norm can be influenced by heterogeneous selection (Bradshaw, 1965; Levins, 1968), 
extending similar findings of studies of more common and widespread taxa (Cook \& Johnson, 1968; Hickman, 1975; Zimmerman, 1976; Wilken, 1977; Bazzaz \& Carlson, 1982; Lotz \& Spoormakers, 1988; Newman, 1988; Andersson, 1989; Bierzychudek, 1989; Trexler \& Travis, 1990).

Of course, we cannot rule out other possible reasons why the reaction norms are different, particularly as the two localities could differ for a wide range of variables not considered in this study. Also, it is important to stress that environmental tolerance can evolve without the presence of spatial variation; artificial selection experiments show that selection for mean performance in a single environment sometimes results in a correlated change in the extent of sensitivity across a range of environments (Jinks \& Pooni, 1982). Finally, in view of the rapid decline of $S$. integrifolius in Sweden, the changes in ecological amplitude (as implied in the present study) may not be of sufficient magnitude to permit long-term maintenance of the remaining populations. In the remainder of this discussion we examine the degree to which genetic constraints could prevent the evolution of broader ecological tolerance in this species.

\section{Within-population variation in response}

Although the current investigation demonstrates small but consistent population differences in shade tolerance, there was little evidence for variation among fullsib groups in their response to light intensity once the effect of population had been accounted for, contrasting with findings of extensive within-population variation in plasticity in other studies (Westerman, 1970; Gupta \& Lewontin, 1982; Via, 1984a; Silander, 1985; Shaw, 1986; Lotz \& Spoormakers, 1988; Taylor \& Aarssen, 1988; Bierzychudek, 1989; Trexler \& Travis, 1990; Weis \& Gorman, 1990; Mazer \& Schick, 1991; Schmitt et al., 1992). Hence, given the high levels of heritable variation detected within light regimes (this study; see also Widén \& Andersson, 1993) and leaving aside the possibility that the (additive) genetic variance may be confounded with other sources of variation (Falconer, 1981), there appears to be a potential for selection to increase the overall performance across the light gradient but little opportunity for specialization to particular light regimes. However, we point out that the statistical power to detect genotype-environment interaction may have been limited due to low replication within full-sib families.

Recently, there has been considerable interest in genetically-based trade-offs within the reaction norm and other constraints that might prevent organisms from maximizing their fitness in every environment
(Huey \& Hertz, 1984; Via \& Lande, 1985; Van Tienderen, 1991; Gabriel \& Lynch, 1992; Gomulkiewicz \& Kirkpatrick, 1992). The search for trade-offs in the present study was motivated by the possibility that populations of $S$. integrifolius may be prevented from becoming adapted to both high and low light intensities. However, contrary to expectation, we found little evidence for negative correlations between fitness measured in different light environments. The mean family performance in full daylight was either uncorrelated or significantly positively correlated with the performance in shade, suggesting a limited potential for trade-offs to retard the simultaneous adaptation to both environments. Because all across-environment correlations were found to be significantly smaller than one, there is a possibility that the heritable differences within light regimes have a different genetic basis and that selection can act independently on different parts of the reaction norm.

A serious objection to these interpretations is that the full-sib correlations may be biased upwards by dominance effects that could easily obscure existing trade-offs (Falconer, 1981; Via, 1984b). However, similar results were obtained by Widén \& Andersson (1993) who used a paternal half-sib design to reveal additive genetic correlations across light regimes for a wide variety of traits connected with fitness. Moreover, the 'realized' changes in the average reaction norm as revealed in the population comparison also argue against strong trade-offs as there was no change in the ranking of population means across the two light regimes: while genotypes from the partially shaded Grödby population exhibited the greatest shade tolerance, they still maintained a high fitness under conditions simulating the presumably original habitat (full sunshine).

The presence of genetic variation within environments and the (apparent) lack of trade-offs within the reaction norm lead to the suggestion that historical or ecological factors may be more important than genetic constraints in preventing $S$. integrifolius from adapting to higher levels of competition. For instance, the rapid invasion of shrubs at ungrazed sites (Widén, 1987) suggests that the large differences in spatial heterogeneity between present-day populations may be of fairly recent origin, a factor that could explain the relatively small differences in the average reaction norm seen in the present study.

\section{Acknowledgements}

We are indebted to A. Peykani, H. Persson and L. Cordona for technical assistance and to R. G. Shaw and an anonymous referee for critically reading an 
earlier version of the manuscript. During the preparation of this paper S. A. was supported by the Swedish Natural Science Research Council. Financial support to B. W. by the Swedish Environmental Protection Agency is also acknowledged.

\section{References}

Andersson, s. 1989. Phenotypic plasticity in Crepis tectorum (Asteraceae). Pl. Syst. Evol., 168, 19-38.

BAZZAZ, F. A. AND CARLSON, R. W. 1982. Photosynthetic acclimation to variability in the light environment of early and late successional plants. Oecologia, 54, 313-316.

BENNETT, A. F., DAO, K. M. AND LENSKI, R. E. 1990. Rapid evolution in response to high-temperature selection. Nature, 346, $79-81$.

BIERZYCHUDEK, P. 1989. Environmental sensitivity of sexual and apomictic Antennaria: do apomicts have general purpose genotypes? Evolution, 43, 1456-1466.

BRADSHAW, A. D. 1965 . Evolutionary significance of phenotypic plasticity in plants. Adv. Genet., 13, 115-155.

COOK, S. A. AND JOHNSON, M. P. 1968. Adaptation to heterogeneous environments. I. Variation in heterophylly in Ranunculus flammula L. Evolution, 22, 496-516.

FAlCONER D. S. 1981. Introduction to Quantitative Genetics, 2nd edn. Longman, London.

FRY, J. D. 1990. Trade-offs in fitness on different hosts: evidence from a selection experiment with a phytophagous mite. Am. Nat., 136, 569-580.

GABRIEI., W. AND LYNCH, M. 1992. The selective advantage of reaction norms for environmental tolerance. J. Evol. Biol., $5,41-59$.

GOMULKIEWICZ, R. AND KIRKPATRICK, M. 1992. Quantitative genetics and the evolution of reaction norms. Evolution, 46, 390-411.

GUPTA, A. P. AND LEWONTIN, R. C. 1982. A study of reaction norms in natural populations of Drosophila pseudoobscura. Evolution, 36, 934-948.

HAMRICK, J. L. AND GODT, M. J. w. 1990. Allozyme diversity in plant species. In: Brown, A. H. D., Clegg, M. T, Kahler, A. L. and Weir, B. S. (eds) Plant Population Genetics, Breeding and Genetic Resources, pp. 43-63. Sinauer Associates, Sunderland, MA.

HICKMAN, J. C. 1975. Environmental unpredictability and plastic energy allocation strategies in the annual Polygonum cascadense (Polygonaceae). J. Ecol, 63, 689-701.

HUEY, R. B, AND HERTZ, P. E. 1984. Is a jack-of-all-temperatures a master of none? Evolution, 38, 441-444.

JINKS, J. L. AND POONI, H. S. 1982. Determination of the environmental sensitivity of selection lines of Nicotiana rustica by the selection environment. Heredity, 49, 291-294.

KUNIN, w. E. AND GASTON, K. J. 1993. The biology of rarity: patterns, causes and consequences. Trends Ecol. Evol., 8, 298-301.

LEviNS, R. 1968. Evolution in Changing Environments. Princeton University Press, New Jersey.

LOTZ, L. A. P. AND SPOORMAKERS, L. D. H. 1988. Differentiation in reproductive characteristics within a population of
Plantago major L. ssp. pleiosperma Pilger. Acta Oecologia, 9, 11-18.

MAZER, S. J. AND SCHICK, C. T. 1991. Constancy of population parameters for life history and floral traits in Raphanus sativus L. I. Norms of reaction and the nature of genotype by environment interactions. Heredity, 67, 143-156.

MILLER, T. E. AND SCHEMSKE, D. W. 1990. An experimental study of competitive performance in Brassica rapa (Cruciferae). Am. J. Bot., 77, 993-998.

NEWMAN, R. A. 1988. Adaptive plasticity in development of Scaphiopus couchii tadpoles in desert ponds. Evolution, 42, 774-783.

REGNELL, G. 1976. Naturreservatet Benestad backar vegetation och flora. Svensk bot. Tidskr., 70, 17-42 (in Swedish).

SCHMAlhausen, I. I. 1949. Factors of Evolution. Blakeston, Philadelphia.

SCHMITT, J., NILES, J. AND WULFF, R. D. 1992. Norms of reaction of seed traits to maternal environments in Plantago lanceolata. Am. Nat., 139, 451-466.

SHAW, R. G. 1986. Response to density in a wild population of the perennial herb Salvia lyrata: variation among families. Evolution, 40, 492-505.

SILANDER, J. A. 1985. The genetic basis of the ecological amplitude of Spartina patens. II. Variance and correlation analysis. Evolution, 39, 1034-1052.

STEARNS, S. C. AND KOELla, J. C. 1986. The evolution of phenotypic plasticity in life history traits. I. Prediction of norms of reaction for age- and size-at-maturity. Evolution, 40, 893-913.

TAYLOR, D. R. AND AARSSEN, L. W. 1988. An interpretation of phenotypic plasticity in Agropyron repens (Gramineae). Am. J. Bot., 75, 401-413.

TREXleR, J. C. AND TRAvis, J. 1990. Phenotypic plasticity in the sailfin molly, Poecilia latipinna (Pisces: Poeciliidae). I. Field experiments. Evolution, 44, 143-156.

VAN TIENDEREN, P. H. 1991. Evolution of generalists and specialists in spatially heterogeneous environments. Evolution, 45, 1317-1331.

VIA, S. 1984a. The quantitative genetics of polyphagy in an insect herbivore. 1. Genotype-environment interaction in larval performance on different host plant species. Evolution, 38, 881-895.

VIA, S. $1984 \mathrm{~b}$. The quantitative genetics of polyphagy in an insect herbivore. II. Genetic correlations in larval performance within and among host plants. Evolution, 38, 896-905.

VIA, S. AND LANDE, R. 1985. Genotype-environment interaction and the evolution of phenotypic plasticity. Evolution, 39, 505-522.

WEIS, A. E. AND GORMAN, W. L. 1990. Measuring selection on reaction norms: an exploration of the Eurosta-Solidago system. Evolution, 44, 820-831.

WESTERMAN, J. M. 1970. Genotype-environment interaction and developmental regulation in Arabidopsis thaliana. IV. Wild material; analysis. Heredity, 26, 383-395.

WIDÉN, B. 1987. Population biology of Senecio integrifolius (Compositae), a rare plant in Sweden. Nord. J. Bot., 7, $687-704$. 
WIDÉN, B. 1991a. Phenotypic selection on flowering phenology in Senecio integrifolius, a perennial herb. Oikos, 61, 205-215.

WIDÉN, B. 1991b. Environmental and genetic influences on phenology and plant size in a perennial herb, Senecio integrifolius. Can. J. Bot., 69, 209-217.

WIDÉN, B. AND ANDERSSON, S. 1993. Quantitative genetics of life-history and morphology in a rare plant, Senecio integrifolius. Heredity, 70, 503-514.
WILKEN, D. H. 1977. Local differentiation for phenotypic plasticity in the annual Collomia linearis (Polemoniaceae). Syst. Bot., 2, 99-108.

YAMADA, Y. 1962. Genotype by environment interaction and genetic correlation of the same trait under different environments. Jap. J. Genet., 37, 489-509.

ZIMMERMAN, C. A. 1976. Growth characteristics of weediness in Portulaca oleracea. Ecology, 57, 964-974. 